\title{
Por un enfoque integral de la violencia familiar
}

\section{Towards a comprehensive approach of family violence}

\section{José Manuel ALONSO VAREA* José Luis CASTELLANOS DELGADO**}

\section{RESUMEN}

Las manifestaciones de violencia que tienen su origen o justificación en procesos disruptivos intrafamiliares cada vez se detectan más por los profesionales, a la vez que se reduce la aceptación de estas situaciones por parte de las víctimas en una sociedad que tiende a asumir como uno de sus valores fundamentales la tolerancia cero frente a este tipo de conductas. Los enfoques tradicionales basados en la atención de la victima y el agresor, además de parciales y a posteriori, olvidan los numerosos puntos en común que tienen estos fenómenos. Un enfoque integral de la violencia familiar debería, en primer lugar, orientarse hacia la prevención de la violencia en este ámbito creando competencias de comunicación, relación afectiva y disciplina que superen las habituales asociaciones entre violencia-machismo-autoridad. En este articulo, los autores exponen los puntos en común y las diferencias más significativas entre las distintas manifestaciones de la violencia familiar (contra los niños, contra la pareja y contra las personas mayores), concluyendo con las ventajas, sobre todo a nivel preventivo, de un enfoque integral.

\section{PALABRAS CLAVE}

Violencia familiar, Maltrato, Prevención de la violencia.

\section{ABSTRACT}

Signs of violence stemming from family disruptive processes are more and more common and reported in a society that is becoming zero-tolerant to this kind of behaviours.

\footnotetext{
* Psicólogo consultor. josem@alonsovarea.com. Máster en Administración Pública (ESADE). Director del postgrado on line sobre violencia familiar. www.il3.ub.edu/infocurso12.ntml

** Psicólogo. Jefe del Área de Programas Sociales de Infancia. Ministerio de Trabajo y Asuntos Sociales.
} 
Apart from being partial and reactive, traditional approaches based on the attention to both victim and attacker forgets many issues that these events have in common. In order to break the traditional link between violence, male chauvinism and authority, the comprehensive approach to family violence should first aim at violence prevention through the promotion of communication skills, affective relationships and discipline, This paper outlines significant commonalities and differences between the various signs of family violence. It also demonstrates the advantages of using a comprehensive approach, mainly at a preventive level.

\section{KEY WORDS}

Family violence, Ill-treatment, Violence prevention. 


\section{AGRESIVIDAD Y VIOLENCIA}

\subsection{Definición de violencia}

Es dificil ofrecer una definición única de violencia ya que se trata en primer lugar de un têrmino coloquial que expresa muchas y muy diversas situaciones. Parece, ante todo, que se trata de un fenómeno complejo que puede abordarse desde muy diversas ópticas. El debate, por ejemplo, sobre el origen cultural o innato de la violencia sigue presente en nuestra sociedad y refleja la multiplicidad de causas que la literatura científica ha relacionado con la aparición de las conductas violentas (biológicas, psicológicas o sociales). Existe un importante grado de acuerdo en ciertas condiciones que debe reunir una conducta para ser definida como violenta (Doménech/Iñiquez, 2002): necesidad de un contexto social interpersonal o intergrupal, intencionalidad y daño como consecuencia del acto agresivo. González (2003) define violencia como acción de carácter intenso realizada con la intención de herir 0 dañar a alguien o a algo, pero con algunos matices diferenciadores como son su intensidad y su carga peyorativa, que no siempre están presentes en las conductas agresivas. Esta definición abre el paso a una variante positiva de la agresividad, en el sentido de conductas con una carga adaptativa o de supervivencia. En esta misma línea, introduciendo una interesante diferenciación entre agresividad y violencia, J.Sanmartin (2000) opina que "considerar que la agresividad es innata en el ser humano no conlleva reconocer que, para el ser humano, es inevitable comportarse agresivamente". Es decir, el ser humano es agresivo por naturaleza, pero pacifico o violento según la cultura en la que se desarrolle.

Sin embargo, la explicación mas cómoda para nuestra cultura, que todavía es básicamente violenta, a la violencia que observamos y padecemos es que los humanos somos seres violentos por naturaleza. Según este punto de vista no podríamos prevenir la violencia con ningún tipo de medida, ni pedir responsabilidades ni hacer gran cosa para reducir la violencia ni los violentos se verían impulsados a cambiar pues serian así de forma innata e inevitable.

En el cuadro 1 se esquematizan algunas diferencias entre la agresividad, que tendría un sentido adaptativo, y la violencia que tendría un componente básicamente cultural. Es la cultura la que convertiria la agresividad en violencia, pues hasta los instintos pueden ser modelados por la cultura. Podemos definir como violencia "cualquier acción (o inacción) que tiene la finalidad de causar un daño (físico o no) a otro ser humano, sin que haya beneficio para la eficacia biológica propia” (J. Sanmartin, 2000). La violencia seria, pues, gratuita desde el punto de vista biológico, y resultado de la interacción entre la agresividad natural y la cultura.

Cuadro 1. Diferencias entre agresividad y violencia

\begin{tabular}{|l|l|}
\hline \multicolumn{1}{|c|}{ AGRESIVIDAD } & \multicolumn{1}{c|}{ VIOLENCIA } \\
\hline Innata & Humana \\
Inevitable & Evitable \\
Biológica & No biológica \\
La cultura puede inhibirla & Resultado de la evolución cultural \\
Impulso para la supervivencia & Utiliza instrumentos \\
\hline
\end{tabular}


Por su valor normativo resulta útil recoger aquí la definición de violencia de la fuerza fisica o el poder, ya sea en grado de amenaza o efectivo, contra uno mismo, otra persona o un grupo o comunidad, que cause o tenga muchas posibilidades de causar lesiones, muerte, daños psicológicos, trastornos del desarrollo o privacidad.

Por su valor normativo resulta útil recoger aquí la definición de violencia de

\subsection{Manifestaciones de la violencia}

Los fenómenos violentos están presentes en todos los contextos de los seres humanos y evidentemente, existen relaciones entre aquellas manifestaciones de violencia que se dan dentro y fuera del entorno familiar. Un clima social tolerante con la violencia es uno de los factores macrosociales que puede favorecer la aparición de violencia familiar, a su vez

Cuadro 2. Algunas manifestaciones de violencia en diferentes ámbitos extrafamiliares

\begin{tabular}{|c|c|c|}
\hline ÁMBITOS & MANIFESTACIONES & DIMENSIÓN DE GÉNERO \\
\hline ESTRUCTURAL & $\begin{array}{l}\text { Injusticia social, } \\
\text { racismo, etc. }\end{array}$ & Infanticidio femenino \\
\hline $\begin{array}{l}\text { ECONOMICA } \\
\text { LABORAL }\end{array}$ & $\begin{array}{l}\text { Acoso físico o moral en } \\
\text { el trabajo (mobbing) } \\
\text { Explotación laboral } \\
\text { (menores, etc, ) } \\
\text { Explotación sexual de } \\
\text { menores }\end{array}$ & $\begin{array}{l}\text { Acoso sexual } \\
\text { Diferente remuneración } \\
\text { Menores oportunidades de empleo y } \\
\text { promoción } \\
\text { Tráfico y explotación sexual de mujeres y } \\
\text { niñas } \\
\text { Prostitución forzosa }\end{array}$ \\
\hline ESCOLAR & Entre iguales (bullying) & - \\
\hline $\begin{array}{l}\text { MEDIOS DE } \\
\text { COMUNICACIÓN } \\
\text { Y OCIO }\end{array}$ & $\begin{array}{l}\text { Escritos, pantallas: } \\
\text { cine, tv, videojuegos, } \\
\text { internet, etc. }\end{array}$ & Publicidad sexista \\
\hline $\begin{array}{l}\text { CONFLICTOS } \\
\text { ARMADOS/ } \\
\text { TERRORISMO }\end{array}$ & $\begin{array}{l}\text { Violencia derivada de } \\
\text { los conflictos armados, } \\
\text { refugiados, } \\
\text { desplazados, etc. }\end{array}$ & $\begin{array}{l}\text { Acoso, violaciones, tráfico y explotación } \\
\text { sexual de mujeres y niñas } \\
\text { Prostitución forzosa }\end{array}$ \\
\hline SEXUAL & Violencia sexual & $\begin{array}{l}\text { Violaciones } \\
\text { Mutilación genital femenina }\end{array}$ \\
\hline DEPORTIVA & $\begin{array}{l}\text { Violencia en el deporte } \\
\text { (agresiones físicas y } \\
\text { verbales) }\end{array}$ & Agresiones verbales \\
\hline EN LA CALLE & Agresiones Fisicas & $\begin{array}{l}\text { Agresión Sexual } \\
\text { Violación }\end{array}$ \\
\hline
\end{tabular}

la OMS (2002). "El uso deliberado de la fuerza física o el poder, ya sea en grado de amenaza o efectivo, contra uno mismo, otra persona o un grupo o comunidad, que cause o tenga muchas posibilidades de causar lesiones, muerte, daños psicológicos, trastornos del desarrollo o privaciones"'. la violencia familiar puede producir manifestaciones violentas dentro y fuera de la familia: como en el caso de la violencia entre iguales en el caso de niños y adolescentes que viven un clima familiar violento, agresiones a maestros, etc. En el cuadro 2 señalamos algunas manifestaciones de la violencia en diferentes 
ámbitos sociales que influyen en las familias. Existe una cierta aceptación social de la violencia fuera de las familias que facilita la violencia dentro de ellas. En la mayoría de estas manifestaciones podemos encontrar:

- Componentes de violencia física, psicológica, intimidaciones, amenazas y coacciones.

- La dimensión de género fruto de procesos de socialización diferenciales en función del sexo del individuo.

\section{LA VIOLENCIA FAMILIAR}

A comienzos de la década de los '70 se comenzó a hablar en algunos países occidentales de la violencia dentro de las familias, iniciando un camino de superación de la invisibilidad de este fenómeno ante la pantalla de privacidad intrafamiliar que fue creciendo en la misma medida en que crecía el reconocimiento y especificidad de los derechos humanos a colectivos como mujeres, niños/as y discapacitados. La violencia familiar, en general, $y$ los malos tratos infantiles, en particular, son algunos de los problemas más graves que afectan negativamente al desarrollo y socialización de los niños y niñas (Gelles, 1993).

A pesar de las condenas de la sociedad y de las leyes contra la violencia familiar, todavia se tiende a diferenciar entre niveles aceptables de violencia familiar y los niveles inaceptables. Un ejemplo de esta diferenciación queda patente en los datos disponibles sobre la aceptación del castigo físico en España. En efecto, los datos aportados por el CIS (Barómetro 2004) señalan que mientras el $85,4 \%$ de los encuestados estaría dispuesto a denunciar a alguien que maltratara a un niño, el 57\% estaría dispuesto a pegarle un azote.
Los estudios retrospectivos muestran que los patrones de disciplina muy coercitivas o contradictorias, que mezclan episodios de fuerte castigo físico con otros de permisividad, son un indicador de riesgo y conflicto social. Pero a la población y a los profesionales les cuesta reconocer el riesgo que representan este tipo de conductas y la necesidad de ofrecer pautas de autoridad y crianza alternativas al comportamiento violento.

Culturalmente, de forma errónea, se ha asociado autoridad con violencia lo cual ha ayudado a legitimar la violencia como una pauta adecuada de autoridad. Igualmente de forma errónea se ha asociado amor con violencia y castigo con violencia. En realidad, la violencia es el uso del poder en negativo. Otras formas de poder son el amor y la autoridad (uso del poder en positivo). A su vez, el castigo puede ser violento (físico, psicológico o sexual) o no violento (disciplina positiva) (Horno, P. 2005). Esta autora detalla una metodología de trabajo con adultos en donde se desmontan estos conceptos que favorecen el castigo físico y psicológico como herramienta educativa. Hace énfasis en que la creación de vinculos afectivos entre los seres humanos (ya sea entre padres e hijos o entre miembros de la pareja) pasa igualmente por mostrar interés por el otro, compartir tiempo para conocerlo, comprometerse, estar a su lado en dificultades, escucharlos, aceptarlos como son mas allá de las expectativas sobre ellos, ser asertivos y compartir actividades y diversión.

Autores como K. Browne y R.J. Gelles sugieren un enfoque global sobre el origen y el mantenimiento de la violencia familiar que supera la visión reducida de cada grupo de profesionales que atiende a cada tipo de víctima y de agresor. Estos profesionales, con demasiada frecuencia, tienen una visión excesivamente centrada solo en la mujer, o solo en los niños o solo en los 
agresores, lo cual impide dar una respuesta de ayuda y de limites adecuados a todos los miembros del núcleo familiar.

La utilización de la denominación "violencia familiar" no supone en ningún caso la equiparación de los dos términos que la componen. Al contrario estimamos que se trata de una perspectiva útil de estudio y de intervención temprana en unos fenómenos que cada día están más presentes en nuestra sociedad.

\section{1 - ¿Qué es la violencia familiar?}

La violencia familiar es...

- "Todo acto u omisión sobrevenido en el marco familiar por obra de uno de sus componentes que atente contra la vida, la integridad corporal 0 psíquica, o la libertad de otro componente de la misma familia, o que amenace gravemente el desarrollo de su personalidad" (Consejo de Europa, 1986).

- Abuso de poder, sobre personas percibidas vulnerables por el agresor pues está asociado con variables como el género y la edad de las víctimas y, entre ellas, las más vulnerables son las mujeres, los niños, los adolescentes, las personas mayores y las personas con algún tipo de disminución (física, psíquica o sensorial). La relación de abuso es una situación en la que una persona con más poder abusa de otra con menos poder para controlar la relación.

- Una forma de violencia estructural, pues para que ocurra es necesario un cierto nivel de aceptación y tolerancia social (de la cultura, el derecho, la ideologia, etc.) hacia esa violencia.
- Un tema politico, la violencia familiar causa más víctimas que la violencia politica terrorista.

- La expresión de dinámicas familiares anomicas, basadas en una desigualdad o asimetría de poder.

Igualmente, la violencia familiar:

- No tiene cultura, raza, sexo, clase social ni edad.

- Se basa en el excesivo "respeto" hacia la vida privada: la sociedad se resiste a intervenir.

- Es un estilo de vida: por frecuente se la considera normal. Se la ha de hacer visible e inadmisible.

- Silenciarla es generarla: consentir modelos inadecuados.

- Afecta a los derechos humanos no sólo de las mujeres, también de niños, adolescentes y mayores, hay que tener en cuenta, asimismo, la incidencia de los fenómenos violentos intrafamiliares ejercidos contra la personas con discapacidad.

- Hace referencia a las distintas formas de relación abusiva que caracterizan de modo permanente o cíclico al vinculo intrafamiliar y alude, por tanto, a todas las formas de abuso que tienen lugar en las relaciones entre los miembros de una familia.

Merece especial atención la profusión y falta de consenso sobre la terminología de estos fenómenos (Violencia domestica, violencia de genero, violencia de pareja, etc). Nuestra propuesta opta por la denominación violencia en la pareja, frente a otras denominaciones como:

- Violencia domestica. Este concepto 
nos remite al espacio físico, no sugiere relaciones, y no tiene en cuenta por tanto los casos en que no hay convivencia o cuando la pareja está separada o divorciada. La violencia en la pareja no acaba en el matrimonio ya que incluye la violencia contra la mujer en las parejas que conviven sin estar casadas, en las parejas que aun no conviven y en las parejas que ya se han separado. Además en este espacio domestico se dan otros tipos e malos tratos además de contra las mujeres.

- Violencia de género o machista. Este concepto incluye toda la violencia contra las mujeres no solo la violencia contra las mujeres en el ámbito familiar, una de las expresiones más frecuentes de la violencia de género. En la pareja no solo se produce violencia contra las muje- res sino también violencia contra la pareja masculina y también podemos encontrar violencia entre las parejas del mismo sexo. Así pues, la violencia hacia la mujer en la pareja es uno de los subtipos de violencia de género.

En la figura 1 se representan las principales manifestaciones de la violencia familiar y los principales agentes involucrados.

Detectar cualquiera de estos tipos de malos tratos depende de la concienciación, del conocimiento y de la comprensión social, colectiva e individual que se tenga del problema. Estas premisas determinan lo que ha de ser reconocido como un maltrato, clasificado como tal y por tanto susceptible de actuar sobre el. Para entender la ocultación del maltrato podemos revisar el modelo de H. Blumer

Figura 1.Tipos de violencia intra-familiar y su ciclo de desarrollo (modificado de Browne, K./Herbert, M., 1997)

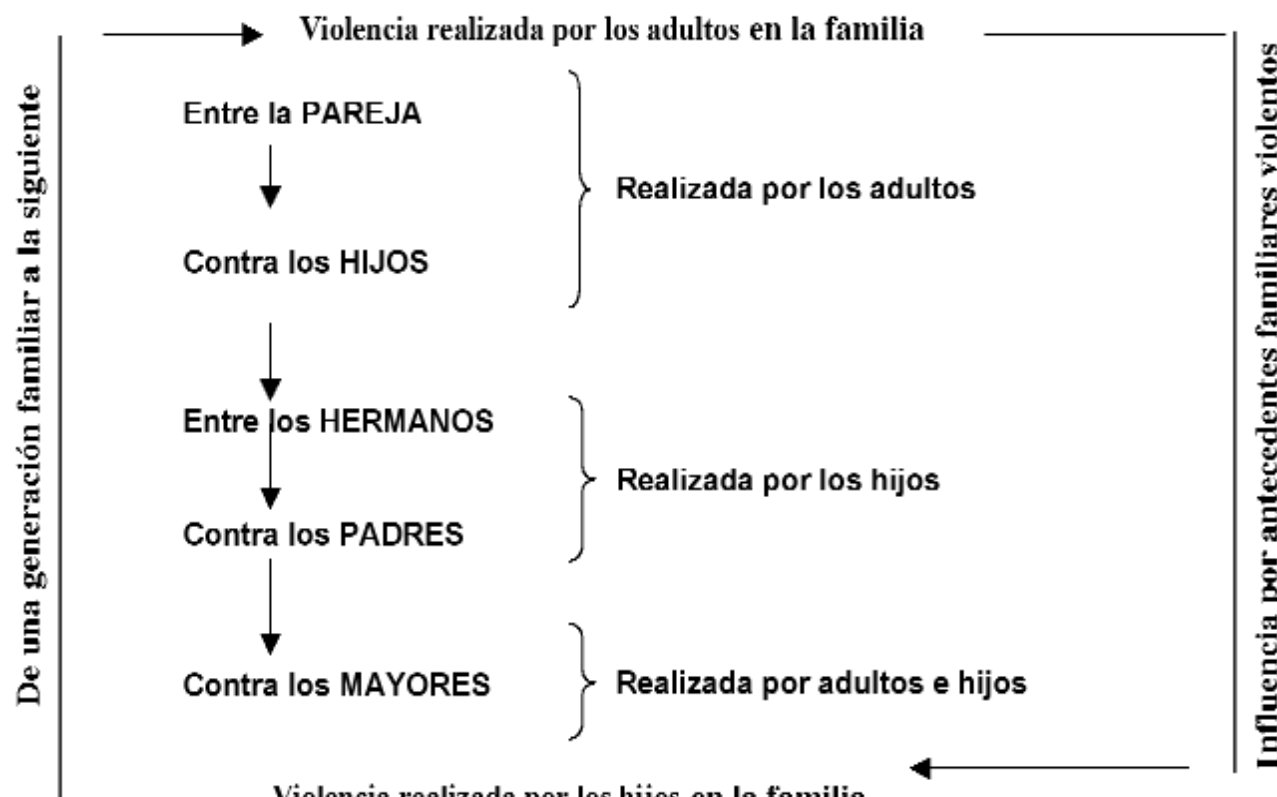

Violencia realizada por los hijos en la familia 
(1971) aplicado a los problemas públicos mediante el cual especifica que "un problema social existe principalmente en los términos en que es definido y concebido en la sociedad". Asimismo prevé la existencia de las 5 etapas siguientes:

1. Emergencia del problema en una sociedad

2. Legitimación del problema por parte de la misma.

3. Movilización hacia la acción con respecto al problema.

4. Formulación de un plan oficial de acción por parte de los estamentos representativos.

5. Implementación de este plan.

En España en el caso de la violencia entre la pareja y de los malos tratos hacia la infancia habriamos entrado muy recientemente en la quinta etapa. Por lo que respecto a los malos tratos a las personas mayores y de la violencia de los hijos contra los padres nos encontrariamos situados entre la primera y segunda etapa.

En esta misma línea la opinión pública sobre el fenómeno de la violencia domestica queda reflejada de forma patente en los barómetros que con carácter periódico realiza el CIS. En concreto, en el realizado en marzo de 2005 , el $91 \%$ de la población cree que la violencia esta muy o bastante extendida hacia las mujeres, el $61 \%$ hacia la infancia y el $53 \%$ hacia las personas mayores. Todos los datos disponibles apuntan, por lo tanto a que, aunque reciente (Doménech/Iñiquez 2002), la violencia familiar reúne todas las condiciones establecidas (Clemente, 1997) para configurarse como un problema social emergente.

\section{2.- ¿Las familias pueden favorecer o evitar la aparición de violencia familiar?}

En nuestra sociedad existe el mito que nos dibuja a la familia como un entorno pacífico e idílico. En efecto, la familia constituye el compromiso social más firme de confianza, protección, apoyo mutuo y amor que existe entre un grupo de personas (Rojas Marcos, 2005). Sin embargo, sus miembros sufren con mayor frecuencia peleas y agresiones de diferente gravedad por parte de sus familiares que las que pueden sufrir en cualquier otro lugar y por cualquier otra persona. Es por ello que se ha definido la familia (Gelles, 1993) como la institución social más violenta de nuestra sociedad, exceptuando el ejército en tiempos de guerra.

La literatura especializada coincide en afirmar que existen dos grandes tipos de carencias o factores que son propiciatorios de la aparición de conductas violentas; se trata de la carencia de recursos (económicos, habitacionales, laborales, sociales, etc) y las dificultades emocionales (empatía, frialdad emotiva, problemas de identidad y autoestima, etc) (Milner, 1999, Gracia, /Musitu, 1993 Pérez/de Paul, 2002).

En cualquier caso, se han identificado algunas caracteristicas especificas de la estructura familiar como grupo social que se exponen en la primera columna del cuadro 3. Paradójicamente, todas estas características pueden ser favorecedoras o bien de un clima enriquecedor, cálido, intimo, de apoyo y de fuente de seguridad (factores de seguridad) o, todo lo contrario, favorecedoras del incremento de tensiones y de violencia entre sus miembros (factores de riesgo), tal y como se muestra en la segunda columna del mismo cuadro. 


\section{Cuadro 3. Características de protección y de riesgo de las familias (Adaptado de R. J. Gelles/M. Straus (1979) y M. Straus/G. Hotaling (1979) citados por R. J. Gelles (1997)}

\begin{tabular}{|c|c|}
\hline $\begin{array}{l}\text { CARACTERISTICA DE LA } \\
\text { CONVIVENCIA FAMILIAR }\end{array}$ & PROTECCION/ RIESGO \\
\hline $\begin{array}{l}\text { Los miembros suelen } \\
\text { pasar mucho tiempo } \\
\text { juntos, en función de la } \\
\text { fase del ciclo vital de la } \\
\text { familia en el que se } \\
\text { encuentren } \\
\end{array}$ & $\begin{array}{l}\text { Se pueden realizar una variedad de intercambios positivos entre los diferentes miembros o puede aumentar las } \\
\text { tensiones entre ellos. }\end{array}$ \\
\hline $\begin{array}{l}\text { El nivel de implicación } \\
\text { emocional entre los } \\
\text { miembros es muy } \\
\text { elevado, de hecho es quizá } \\
\text { el entorno en el que hay } \\
\text { mayor implicación de éste } \\
\text { tipo. }\end{array}$ & $\begin{array}{l}\text { Esto puede favorecer el sentimiento de cercania, pertenencia y solidaridad, Por otro lado, los comentarios y } \\
\text { advertencias (positivas o negativas) realizados entre los miembros pueden tener mas intensidad que los } \\
\text { realizados por personas que no son de la familia. }\end{array}$ \\
\hline $\begin{array}{l}\text { Diversidad de actividades } \\
\text { e intereses }\end{array}$ & $\begin{array}{l}\text { Esta diversidad puede ser fuente de riqueza. Sin embargo, en caso de desacuerdo algunos miembros pueden no } \\
\text { estar dispuestos a negociar por lo que puede haber colisión entre intereses percibidos como antagónicos. }\end{array}$ \\
\hline $\begin{array}{l}\text { Se aprenden formas de } \\
\text { gestionar conflictos. }\end{array}$ & $\begin{array}{l}\text { Se puede aprender a negociar intentando que todos salgan beneficiados, o bien, se pueden aprender formas } \\
\text { violentas de resolver conflictos mediante la fuerza, la amenaza, la coacción, etc. }\end{array}$ \\
\hline $\begin{array}{l}\text { Existe el derecho a } \\
\text { influenciar sobre modelos, } \\
\text { valores, actitudes y } \\
\text { conductas }\end{array}$ & $\begin{array}{l}\text { Esta influencia puede realizarse con respeto o bien de una forma autoritaria que no tenga en cuenta las } \\
\text { diferentes necesidades y fases de desarrollo de cada miembro. }\end{array}$ \\
\hline $\begin{array}{l}\text { Diferencias de edad } y \text { de } \\
\text { sexo }\end{array}$ & $\begin{array}{l}\text { Estas diferencias se pueden integrar como modelos con diferente experiencia y puntos de vista. En otras } \\
\text { ocasiones, esto puede suponer una fuente de batallas entre generaciones y sexos }\end{array}$ \\
\hline Asignación de roles & $\begin{array}{l}\text { Los roles y responsabilidades se asignan en base a la edad y al sexo, y no en base al interés de cada miembro } \\
\text { en realizarlos ni en la competencia que tengan para ello. Esto puede potenciar tanto relaciones funcionales como } \\
\text { disfuncionales. }\end{array}$ \\
\hline Privacidad & $\begin{array}{l}\text { Es importante la sensación de seguridad de que el exterior no se va a entrometer. Sin embargo, este } \\
\text { aislamiento a los ojos, oidos y normas de la sociedad hace que pueda haber impunidad y menor control social }\end{array}$ \\
\hline Pertenencia involuntaria & $\begin{array}{l}\text { El hecho de que las relaciones sean involuntarias y no se puedan extinguir puede ayudar a mantener la ayuda } \\
\text { mutua. No obstante, cuando el conflicto aparece no es fácil salir del grupo y no estar implicado }\end{array}$ \\
\hline $\begin{array}{l}\text { Se aprenden formas de } \\
\text { gestionar el estrés }\end{array}$ & $\begin{array}{l}\text { Los diferentes cambios que ocurren en la vida de las familias pueden ser superados entre los diferentes } \\
\text { miembros. Otras veces se tr ansmiten fácilmente los efectos negativos del estrés debido a enfermedades, } \\
\text { desempleo, etc, de un miembro a otro. }\end{array}$ \\
\hline $\begin{array}{l}\text { Hay un conocimiento } \\
\text { profundo de la biografía } \\
\text { de cada miembro }\end{array}$ & $\begin{array}{l}\text { El conocimiento de puntos fuertes o debilidades, de gustos, de miedos, etc, puede ser usado como un factor de } \\
\text { vulnerabilidad para atacar a los demás y provocar conflicto. }\end{array}$ \\
\hline
\end{tabular}




\section{3. Transmisión intergeneracional de la violencia familiar}

Gelles (1980) identifico la aparición de un "ciclo de la violencia" como uno de los principales factores relacionados con la ocurrencia del maltrato infantil y de la violencia conyugal. La transmisión intergeneracional de la violencia (Yanes/Gonzalez, 2000) ha sido estudiada de forma recurrente a partir de los años 60 tratando de buscar un historial de maltrato en los padres maltratadores (Gómez y de Paúl, 2002) y a partir de los años 70 como explicación de la violencia de genero. Presenciar situaciones de violencia familiar es uno de los más potentes factores de riesgo, en el caso de los niños, para repetir esta pauta de conducta en pareja cuando crezcan y, en el caso de las niñas, para asumir un papel pasivo de aceptación de dicha violencia. Así pues, crecer en contextos familiares donde existe violencia es un predictor para la aparición de diversos problemas emocionales, cognitivos y de conducta, tanto a corto como a largo plazo (González 2003). Las pautas educativas que transmiten los padres son fundamentales en la modulación de los conflictos internos de los hijos.

En cualquier caso los datos no son definitivos. A los problemas metodológicos inherentes a investigaciones retrospectivas se añade la certeza de los numerosos casos donde la exposición a la violencia familiar no ha generado patrones de conducta violentos. Por lo tanto, en los últimos años se han puesto en valor interpretaciones que hacen un mayor hincapié en los factores moduladores de tipo cognitivo (creencias), proactivos, que en las tradicionales tesis basadas en las teorías de aprendizaje o del apego.

La toma de conciencia sobre lo que les ocurrió a las victimas durante la infancia y la ayuda por parte de alguna persona cercana sea profesional o no, son algunos de los elementos que pueden contribuir a romper este círculo. Una lectura 0 interpretación positiva de la violencia vivida en la familia de origen puede anular o impedir la repetición de conductas violentas familiares en la próxima generación (Egeland, 1993, González, 2003). Yanes y González (2000) concluyen manifestando la posibilidad de que las creencias estén afectando a la construcción de la experiencia pasada. De hecho, se ha podido comprobar que las personas acomodan sus recuerdos hasta hacerlos compatibles con sus creencias acerca de sus relaciones de pareja (vid. Holmes y Murray, 1995).

\section{MANIFESTACIONES DE VIOLENCIA FAMILIAR}

Trataremos de las principales manifestaciones de violencia familiar (violencia contra niños y adolescentes, en la pareja, y contra personas mayores) no habiéndose incluido a efectos comparativos, las que hemos llamado "otras" formas de violencia familiar (la violencia de hijos contra padres y madres, la violencia entre parejas en periodo de formación y la violencia entre hermanos) que con respecto a la naturaleza o tipología de los actos violentos, la clasificación más aceptada es la recogida por la Organización Mundial de la Salud (2002), según la cual los actos violentos pueden ser físicos, sexuales, psicológicos o basados en las privaciones o el abandono (negligencia). No obstante, resulta particularmente interesante la clasificación de tipos de malos tratos que hace Browne y Herbert, 1997:

\section{Violencia activa, abuso o maltrato}

- Física. Infligir o amenazar con daño o lesiones, por ejemplo: empujones, bofetadas, golpes, estirones de pelo, 
mordiscos, patadas, torcer los brazos, golpear con objetos, quemaduras, etc. Coerción forzada y limitar movimientos físicos.

- Sexual. Contacto sexual sin consentimiento, cualquier contacto sexual coercitivo o con fines de explotación, por ejemplo: caricias, relaciones sexuales vaginales o anales, ataques a zonas sexuales del cuerpo. Obligar a ver imágenes 0 actividades sexuales y amenazar con contactos sexuales.

- Psicológico. Infligir angustia a través del control y limitación de acceso a amigos, escuela o trabajo; aislamiento forzado, ser testigo involuntario de actividades e imágenes violentas; intimidación, usar el miedo o el daño físico, las amenazas, los chantajes, amenazas de suicidio y acoso hacia los demás; destrucción de propiedades y mascotas.

- Emocional. Realizar de forma habitual criticas, humillaciones, denigración, insultos, silenciar, dañar la autoimagen.

- Material (económico). Explotación financiera o ilegal y control de fondos y otros recursos necesarios para la supervivencia económica y personal. Obligar a una persona a ser dependiente económicamente.

\section{Violencia pasiva o negligencia}

- Negligencia voluntaria. Rechazo o fracaso en las obligaciones de cuidar, incluyendo acciones intencionadas de causar stress físico o emocional, por ejemplo: abandono deliberado 0 no proveer de dinero, alimentos, pobre cuidado de la salud ausencia de afecto y de protección sexual, etc.
- negligencia involuntaria. Fracaso en las obligaciones de cuidar, sin intención de causar stress físico 0 emocional, por ejemplo: abandono, no provisión de dinero, alimentos, pobre cuidado de la salud, ausencia de afecto y de protección sexual, etc. debido a ansiedad, conocimiento inadecuado, pereza 0 enfermedad.

Generalmente la violencia psicológica precede y acompaña a la violencia física $\mathrm{y}$ el maltrato intrafamiliar precede al abuso extrafamiliar. Es habitual la coexistencia de diferentes formas de violencia en la misma relación, así como el riesgo de revictimización. Este es debido a que el maltrato incrementa el riesgo de posteriores malos tratos por las mismas personas $\mathrm{u}$ otras de la propia familia $\mathrm{y}$ por personas externas a la familia conocidas o desconocidas. La reproducción del ciclo de violencia familiar puede, en muchas ocasiones, favorecer la aparición sucesiva y a veces simultánea de diferentes tipos de violencia.

\subsection{Las tipologias: principales aspectos comunes y diferenciales}

En el cuadro 4 se esquematizan características comunes y algunas diferenciales entre la violencia contra niños y adolescentes, en la pareja, y contra personas mayores.

\subsection{Las respuestas: principales aspectos comunes y diferenciales}

En el cuadro 5 hacemos énfasis en los aspectos comunes a la intervención en los diferentes tipos de malos tratos, que habitualmente se tienen poco en cuenta. Ello no implica desconsiderar aspectos específicos de la intervención en cada tipo de maltrato. 
Por un enfoque integral de la violencia familiar

Cuadro 4. Principales tipologias de violencia familiar. Aspectos comunes y diferenciales

\begin{tabular}{|c|c|c|c|}
\hline & Infancia y adolescencia & \begin{tabular}{|c|} 
Pareja \\
\end{tabular} & Personas mayores \\
\hline DEFINICION & $\begin{array}{l}\text { Toda violencia, perjuicio o } \\
\text { abuso fisico o mental, descuido } \\
\text { o trato negligente, malos tratos } \\
\text { o explotación, mientras que el| } \\
\text { niñóno se encuentre bajo la } \\
\text { custodia de sus padres, de un } \\
\text { futor o de cualquuiera otra } \\
\text { persona que le tenga a su } \\
\text { cargo (Articulo } 19 \text { de la } \\
\text { Convención de los Derechos del } \\
\text { Niño. 1990) }\end{array}$ & $\begin{array}{l}\text { oTodo acto u om isión, sufrido por la pareja } \\
\text { oque vulnere o ponga en peligro su integridac } \\
\text { sfisica, psiquica, sexual o económica, incluids } \\
\text { all principio de autonomía y el resto de } \\
\text { aderechos fundamentales. } \\
\text { a }\end{array}$ & $\begin{array}{l}\text { Ta,Todo acto u om isión, sufrido por personas } \\
\text { admayores en e I medio familiar, en la } \\
\text { docomunidad o en instituciones que vulnere o } \\
\text { deponga en peligro la integridad fisica, psíquica, } \\
\text { sexual o economica, incluido el principio de } \\
\text { autonomia y el resto de derechos } \\
\text { fundamentales, constatatable objetivamente o } \\
\text { percibido subjetivamente por la persona } \\
\text { ALMERIA (1995) }\end{array}$ \\
\hline $\begin{array}{l}\text { RECONOCIMIENTO } \\
\text { DELL PROBLEMA en } \\
\text { España }\end{array}$ & \begin{tabular}{|c|}
$1980-1990$ \\
Hay estudios nacionales
\end{tabular} & $\begin{array}{c}1990-2000 \\
\text { Hay estudios nacionales }\end{array}$ & $\begin{array}{l}2000 \ldots ? \\
\text { No hay estudios nacionales }\end{array}$ \\
\hline $\begin{array}{l}\text { PLANESY } \\
\text { PROGRAMAS } \\
\end{array}$ & SI & SI & No hay planes nacionales \\
\hline \multicolumn{4}{|c|}{ DATOS DE PREVALENCIA (número de personas que padecen situaciones de maltratos) } \\
\hline $\begin{array}{l}\text { Ambito familiar } \\
\text { El 50\% de las familias } \\
\text { han suffido algún tipo } \\
\text { de violencia } \\
\text { (J.Sanmartin, 2000) }\end{array}$ & \begin{tabular}{|l|} 
Alguna forma de abuso sexual \\
infantili: una de cada cinco \\
niñas (20\%) y uno de cada diez \\
niños (10\%) menores de 17 \\
años (López, 1994) \\
En España en 7 de cada 10000 \\
niños son confirmados los \\
malos tratos (Centro Reina \\
Sofia, 1998) \\
La negligencia, el maltrato \\
emocional y el fisico por este \\
orden, son las formas mas \\
frecuentes \\
\end{tabular} & $\begin{array}{l}\text { El } 75 \% \text { de la violencia en la pareja es } \\
\text { exclusiva contra la mujer, el } 2 \% \text { lo es } \\
2 \text { contra el hombre y en el } 23 \% \text { ambos son } \\
\text { victimas de la violencia reciproca } \\
\text { (J.Sanmartin, 2000). } \\
\text { Objetivamente } 9 \% \text { de las mujeres } \\
\text { Pero solo lo reconocen 2,3\% (Instituto de } \\
\text { la Mujer, 2002) } \\
\text { El 40\% de las mujeres con discapacidades } \\
\text { son maltratadas, } \\
\text { Se producen situaciones de violencia en } \\
\text { 2/3 de las parejas } \\
\text { En España cada semana entre } 1 \text { y } 2 \\
\text { mujeres son asesinadas por sus parejas. } \\
\text { En } 2004 \text { en España, 13,6 mujeres } \\
\text { extranjeras por millón fueron muertas por } \\
\text { su pareja o expareja frente a 2,6 por } \\
\text { millón de las mujeres españolas. Cuando la } \\
\text { mujer acaba la relación: } 75 \% \text { de riesgo de } \\
\text { ser atacada }\end{array}$ & $\begin{array}{l}\text { 6\% (OMS, 2002) } \\
5 \% \text { (INPEA. Red Internacional para la } \\
\text { Prevención del Maltrato a los Mayores) } \\
35 \% \text { de los usuarios mayores de } 65 \text { años } \\
\text { atendidos por servicios sociales (Generalitat de } \\
\text { Cataluña, 1995) } \\
\\
\end{array}$ \\
\hline Ambito residencial & No hay datos & No hay datos & $10 \%$ (INPEA) \\
\hline \multicolumn{4}{|c|}{ IIPOLOGIAS todas se producen mas cuando la persona tiene alguna discapacidad } \\
\hline Maltrato fisico & $x$ & $x$ & $x$ \\
\hline $\begin{array}{l}\text { Maltrato psicológico/ } \\
\text { emocional }\end{array}$ & $x$ & $x$ & $x$ \\
\hline Abuso sexual & $x$ & $x$ & $X$ \\
\hline Negligencia & $x$ & $x$ & $x$ \\
\hline $\begin{array}{l}\text { Institucional/ } \\
\text { vulneración derechos }\end{array}$ & $x$ & $x$ & $x$ \\
\hline
\end{tabular}


Cuadro 4. Principales tipologias de violencia familiar. Aspectos comunes y diferenciales (continuación)

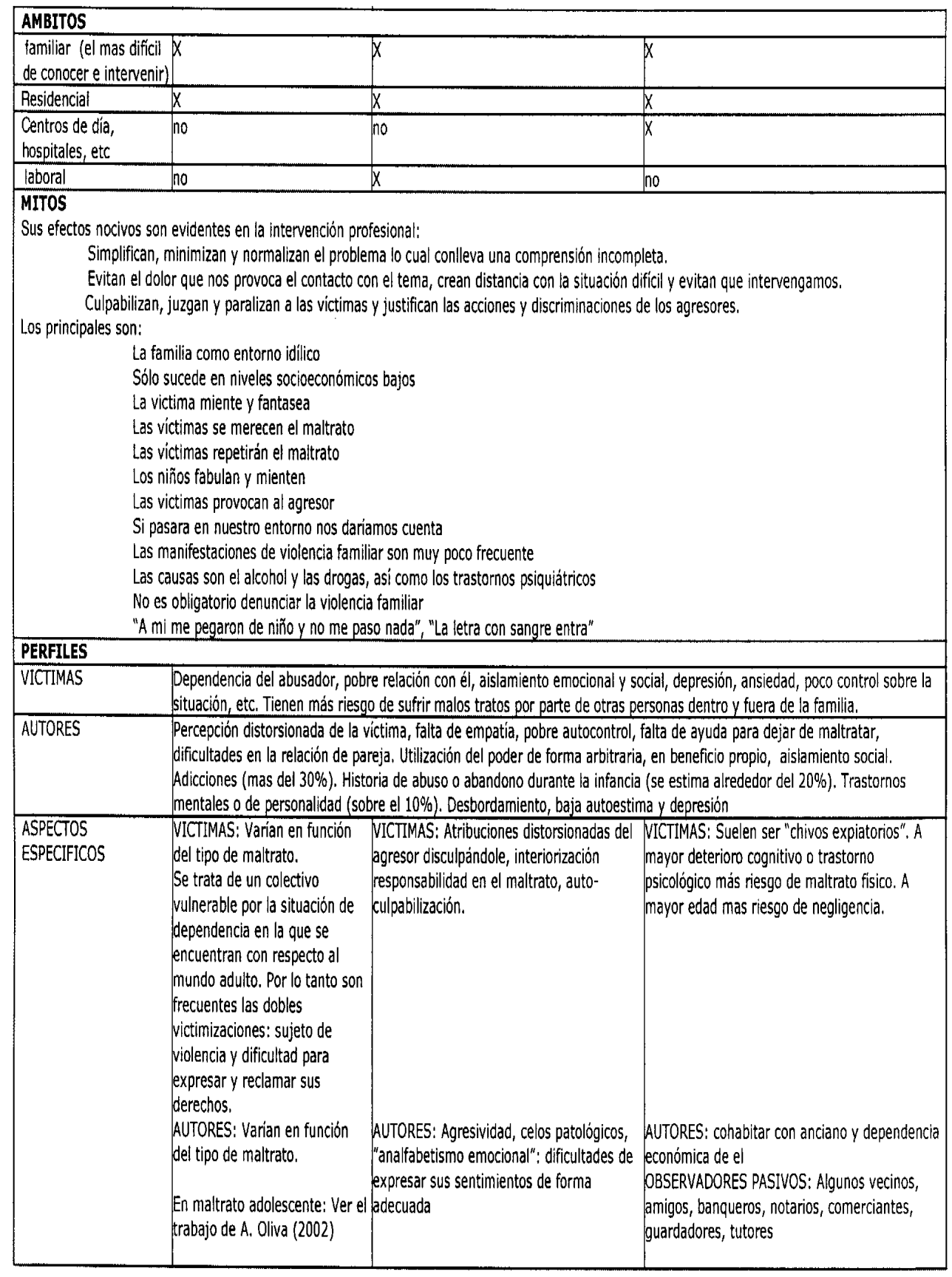


Por un enfoque integral de la violencia familiar

\section{Cuadro 5. Proceso de intervención en violencia familiar. Aspectos comunes y diferenciales}

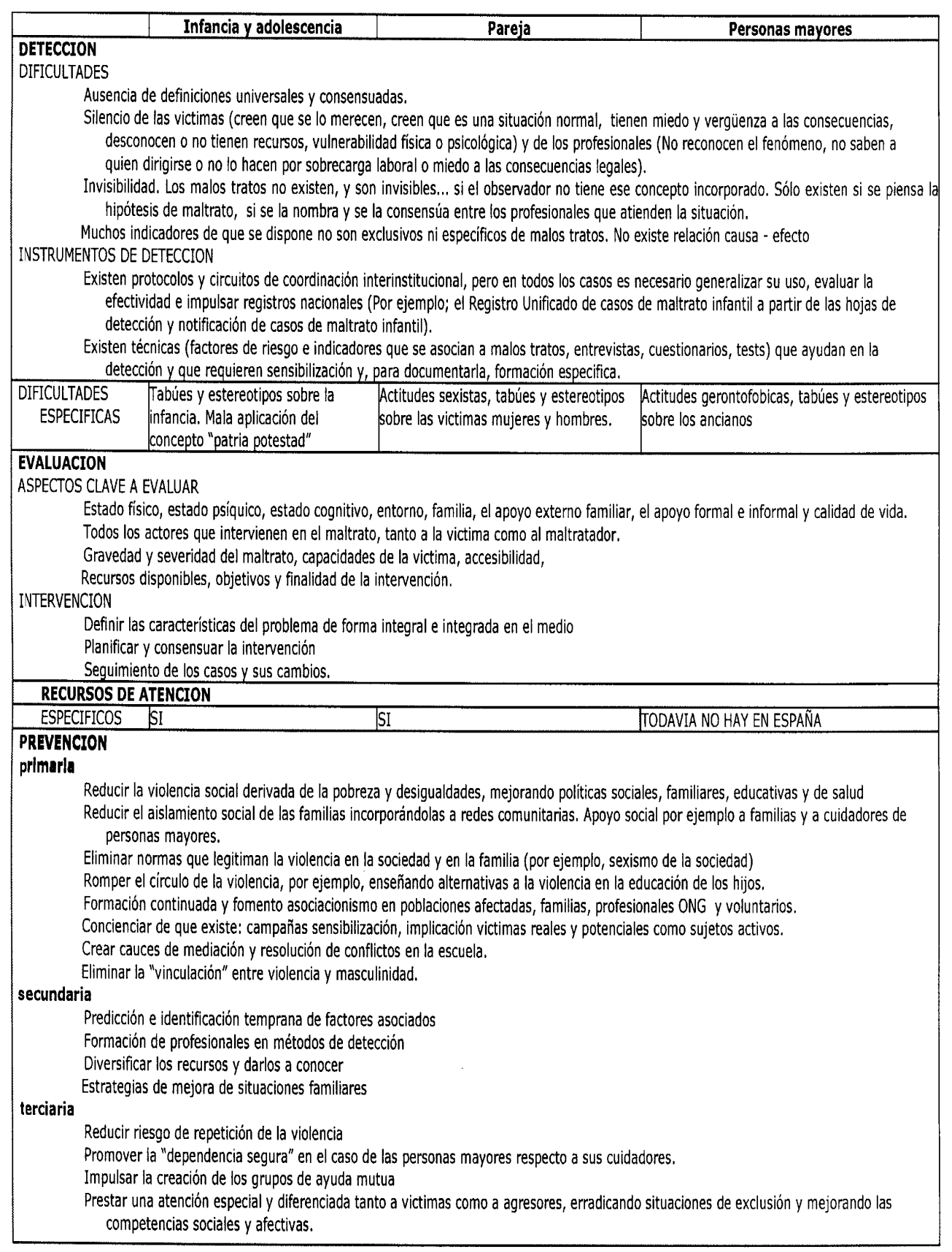




\section{OTRAS FORMAS DE VIOLENCIA FAMILIAR}

Más allá de la violencia contra niños y adolescentes, en la pareja y a las personas mayores, existen otras formas de violencia familiar emergentes, como son la violencia de los niños y adolescentes contra los adultos, la violencia entre parejas jóvenes y la violencia entre hermanos. Todas estas violencias, con orígenes similares, se recogen aquí sobre todo para darles visibilidad a pesar de que hay pocos estudios sobre ellas.

\section{La violencia de los niños y adolescentes contra los adultos}

En los últimos años se esta produciendo en las sociedades occidentales un rápido aumento de agresiones (tanto físicas como psicológicas) de hijos a sus padres. Este hecho esta relacionado con cambios laborales, educativos, tecnológicos, de valores, etc. de nuestras sociedades. Algunos datos son:

- En España en el año 2005 se realizaron 8000 denuncias de padres que habían recibido agresiones de sus hijos (casi 3 veces más que el año anterior)

- Incremento de los delitos de violencia sobre familiares que llegan a las fiscalias de menores (ver cuadro 6).

- Las madres son las víctimas principales de estas agresiones. Puede influir en ello, la cultura machista, la percepción de que son más débiles físicamente y el hecho de que pasen más tiempo con los hijos que los padres.

- En general, la mayor parte de estas agresiones son realizadas por chi- cos varones de clase media y alta (hay una chica cada diez casos), entre 12 y 18 años (especialmente entre 15 y 17 años) (Moreno, 2005). Los padres aguantan demasiado tiempo la violencia de los hijos. Al principio la soportan pensando que es algo "normal" (la edad, la afirmación de la personalidad, etc.). Cuando aumentan en intensidad las agresiones las aguantan por el miedo a exponer su "fracaso" como padres y por pensar que es un tema únicamente familiar que no tiene solución. No se han encontrado factores genéticos en este tipo de agresiones (Chartier, 2000).

Una parte de las agresiones realizadas por menores contra sus padres o familiares engrosan las cifras de la justicia juvenil. Resumiremos una investigación pionera y reciente (Romero y otros, 2005) sobre los 116 expedientes relativos a agresiones de hijos a padres y calificados por los fiscales de menores de Cataluña como hechos de violencia domestica desde enero de 2001 hasta diciembre del 2003

Este tipo de delitos supone el 3\% del total de los registrados en el ámbito juvenil.

Sus principales características son:

- El 79,3\% son chicos, con una tendencia al alza en el caso de las chicas.

- La mayoría nacieron en el Estado español $(91,4 \%)$.

- Tienen dificultades para interiorizar normas y asumir responsabilidades.

- De los menores escolarizados, en un $67,2 \%$ el rendimiento escolar ha sido regular o malo. 
Por un enfoque integral de la violencia familiar

Cuadro 6. Denuncias en las fiscalias provinciales

(Romero, F. y otros, 2005)

\begin{tabular}{|l|c|c|}
\hline & violencia física sobre familiares & $\begin{array}{c}\text { violencia psíquica sobre } \\
\text { familiares o maltrato familiar }\end{array}$ \\
\hline 2001 & 23 & 3 \\
\hline 2002 & 43 & 6 \\
\hline 2003 & 63 & 4 \\
\hline 2004 & 83 & 95 \\
\hline
\end{tabular}

- El 32,8\% refieren problemas conductuales, emocionales o cognitivos que tienen un inicio precoz.

- Hay una importante presencia de conductas violentas en el ámbito social. El 35,3\% manifiestan conductas violentas en la escuela.

- En el 44\% de las familias la convivencia tiene lugar en el núcleo familiar originario y el 56\% vive en diferentes organizaciones familiares fuera del núcleo originario (familias monoparentales, familias reconstituidas, convivencia con familia extensa o en un centro de la Administración).

- El 76,7\% de las familias ha vivido experiencias que ha modificado las características del núcleo familiar (separación de los progenitores, formación de nuevas parejas, muerte 0 distanciamiento de uno de los progenitores, problemas de relación con los hijos). El 62,1\% de las familias tambiên ha presentado dificultades por déficit de las figuras parentales, por el estilo de relaciones establecido o por la presencia de factores distorsionantes (problemas de salud física o mental, adicciones, no aceptación de la nueva pareja del progenitor).

Características del conflicto y de la denuncia.
- La victima mas frecuente es la madre la cual recibe el $87,7 \%$ de las agresiones: sola $(42,2 \%)$, con otros hijos $(16,4 \%)$, con el marido $(15,5 \%)$, con marido e hijos $(6 \%)$, con abuelos $(4,3 \%)$, etc.

- La persona que acostumbra a denunciar con más frecuencia es la madre $(64,7 \%)$.

- En el 78,4\% de los casos hay contacto físico en la agresión, como puñetazos, patadas, empujones, intentos de ahogar. En el 21,6\% de los casos han sido insultos y vejaciones. liares.

Dos grupos de jóvenes agresores fami-

En el primer grupo el único delito que consta en su expediente a justicia de menores es de violencia doméstica (46,6\%), encontramos que:

- Las familias de estos jóvenes son las que presentan un patrón más normalizado o adaptado socialmente (no ha habido cambios en el núcleo de convivencia y el estilo educativo del progenitor consta como adecuado).

- La situación de conflicto tiene una duración anterior a la denuncia de al menos de seis meses. 
El segundo grupo lo forman jóvenes con "carrera delictiva" $(53,4 \%)$, con expedientes abiertos a justicia de menores con motivo de otros tipos penales, antes o después del de violencia doméstica. Las características más asociadas son las siguientes:

- Tienen expedientes tanto anteriores como posteriores en delitos contra las personas y contra la propiedad.

- Consumen sustancias legales (alcohol) e ilegales (cocaina y otras).

- Se dan conductas violentas en la escuela y hacia los iguales.

- Trayectoria escolar con absentismo y cambios de centro.

\section{Violencia entre parejas jóvenes}

Se disponen de escasos datos sobre la violencia entre parejas jóvenes y cuando éstos aparecen, lo hacen de forma muy genérica. Por ejemplo, las propias estadísticas del Instituto de la Mujer informan de la existencia de muertes producidas entre novios o exnovios. Todos los estudios revisados concluyen en la necesidad de realizar esfuerzos basados en la prevención primaria, fundamentalmente en la adolescencia. El cambio de actitudes, valores y estereotipos durante esta etapa y especialmente durante las primeras relaciones afectivas entre parejas de novios pueden repercutir durante las posteriores relaciones entre cónyuges (el tipo de relación familiar en el que aparece la mayor prevalencia y que más muertes ocasiona).

Los datos de Rodríguez Franco/Rodríguez Díaz (2004) indican:
- La existencia de conductas de maltrato en cualquiera de sus modalidades (físico, emocional, sexual, social, etc) entre parejas de novios universitarios, cuya prevalencia se incrementa cuando las encuestas se realizan en el ámbito de Institutos de Educación Secundaria (con cifras que oscilan entre el 3 y el $6 \%$ ).

- Cuando se le pregunta a los estudiantes que mantienen o han mantenido relaciones de pareja acerca del grado en que tales conductas (esto es, las que pueden ser constitutivas de violencia de género), son toleradas e incluso aceptadas los porcentajes llegan a valores muy elevados. De hecho, más del $\mathbf{6 0} \%$ de los encuestados dicen conocer parejas de novios adolescentes que en la actualidad o en los últimos seis meses están o han estado siendo victimas de violencia de género.

- Las peculiares y específicas formas de relación afectiva que se mantienen durante el noviazgo de adolescentes (debidos al nivel de maduración, la inexperiencia y los estereotipos de relación, entre muchos otros), favorecen la mayor prevalencia de ciertos tipos de conductas de violencia de género sobre otros más propios de la edad adulta. La denominación de las mujeres con nombres de genitales, la claridad de las insinuaciones o tocamientos de naturaleza sexual, las "persecuciones" a las que se ven sometidas cuando se desea romper la relación, etc. son un ejemplo de ello.

La relación entre violencia en parejas jóvenes con episodios de violencia en sus familias de origen ha sido recientemente estudiada por González y Santana 
(2001) en una muestra de 1146 estudiantes entre 16 y 18 años. El 12\% de los jóvenes ha presenciado, al menos una vez, como sus padres agreden físicamente a sus madres (empujar o pegar). Sin embargo, solo el 6\% ha observado la misma conducta en sus madres. En sus relaciones de pareja, el 7,5\% de los chicos y el 7,1\% de las chicas señala haber empujado o pegado a su pareja, al menos una vez (obsérvese el porcentaje tan similar entre sexos). Los autores indican que los jóvenes que muestran más agresividad son aquellos que han observado más violencia en sus madres y han recibido más castigo físico de sus padres.

Se ha evaluado la violencia psicológica (agresión verbal, comportamientos dominantes o coercitivos y tácticas celosas) en las relaciones de noviazgo en la juventud (González/ Muñoz, 2004). Analizaron la asociación entre el género y las actitudes que justifican este tipo de violencia, determinando si las variables consideradas pueden ser estimadas como importantes correlatos en la implicación de las conductas violentas en edades tempranas. Trabajaron con una muestra de 221 estudiantes, pertenecientes a diferentes Universidades de la Comunidad de Madrid de diferentes carreras, y con edades comprendidas entre los 18 y 27 años. Sus resultados indican que:

- Durante el noviazgo se presentan episodios violentos, donde la modalidad más frecuente es la psicológica (agresión verbal, comportamientos celosos y tácticas de dominancia). Al comparar los indices de violencia de ambos géneros no se encontraron grandes diferencias significativas.

- Las relaciones existentes entre cada una de las actitudes que justifican las agresiones psicológicas (agresio- nes verbales, tácticas de dominancia y comportamientos celosos) y los comportamientos propiamente dichos, se observan que la mayoría de las correlaciones entre las variables objeto de estudio son significativas, moderadas y positivas.

- La violencia psicológica forma parte de las relaciones afectivas de los adolescentes y jóvenes. Donde las actitudes que justifican el uso de la agresión como forma de resolver los problemas de pareja se considera uno de los aspectos centrales en los programas de prevención, posibilitando la actuación antes de que los estudiantes tengan parejas, y diseñando estrategias que faciliten el cambio de actitudes y el desarrollo de habilidades específicas para detectar y enfrentarse con este tipo de relaciones.

Respecto a las relaciones sexuales no deseadas, un estudio (Ramos/ Fuertes 2005) entre una muestra 485 jóvenes con una media de edad de 20 años, el $40.9 \%$ de las chicas afirma haber mantenido algún tipo de estas relaciones. Las chicas que afirman haber mantenido relaciones sexuales no coitales no deseadas porque un amigo utilizó la presión verbal o le incitó al consumo de alcohol $\mathrm{u}$ otra drogas aceptan en mayor medida que está justificado que el varón emplee estas estrategias si la mujer le ha "provocado" previamente. Por su parte, las mujeres que informan haber mantenido contactos sexuales no coitales porque su pareja utilizó la fuerza física consideran en mayor grado que las mujeres pierden el derecho a decir "no" una vez cruzados determinados limites respecto al resto de chicas.

En una excelente revisión González, R. (2003) encuentra los siguientes factores de riesgo en este tipo de conducta: 
- Presencia de conductas previas humillantes, de control y/o aislamiento.

- Deseo de control sobre la pareja.

- Presencia de violencia en la familia de origen.

- Actitudes tradicionales respecto a roles de genero.

\section{Violencia entre hermanos}

Hay escasa conciencia sobre este tipo de violencia entre la población. De hecho la investigación es escasa aunque la que existe apunta una realidad preocupante. Hay muchos paralelismos entre la violencia entre hermanos y el fenómeno cada vez mas popularizado entre la opinión publica del "bullying" (violencia fisica, psicológica y/o sexual entre iguales sobre todo en la escuela y su entorno) y muchas recomendaciones de intervención y prevención son igualmente similares. De hecho, los niños y adolescentes que suelen ser agresivos en la escuela también suelen serlo dentro de la familia. Después de la no obediencia la agresión es la segunda queja de los adultos que tienen que cuidar a niños con dificultades. Muchos adultos consideran como "normal" la agresión física y verbal entre hermanos, como un buen entrenamiento para gestionar sus relaciones en el mundo exterior. Incluso piensan que mejor eso que no inhibir las conductas agresivas. Sin embargo los estudios científicos señalan que no hay evidencia de que comportándose agresivamente se reduzca la agresividad en general.

Los datos internacionales de los que disponemos nos permiten entrever una realidad incuestionable desde los últimos veinte años:
- En un estudio en USA con una muestra representativa de niños entre 3 y 17 años (Straus, y cols, 1988) el $82 \%$ estaba involucrado durante el último año en un acto agresivo hacia un hermano (lanzar objetos, golpear con un objeto, patadas, mordiscos, etc.).

- Un estudio realizado en Gran Bretaña (Browne/Herbert, 1997) entre estudiantes de secundaria señala que un $2 \%$ de los estudiantes habían sido abusados sexualmente por hermanos cinco años mayor al menos en una ocasión. El abuso sexual entre hermanos a menudo esta asociado con el maltrato físico.

Factores que pueden favorecer la aparición de violencia entre hermanos:

- Ambiente de violencia familiar.

- Familias en las que hay malos tratos hacia los hijos por parte de los padres.

- Ausencia de ambiente calido y afecto positivo.

- Ausencia de reglas claras sobre la disciplina.

- En todas las edades las chicas son menos violentas que los chicos, pero las diferencias son pequeñas.

- A medida que aumenta la edad disminuyen los porcentajes de niños y niñas agredidos por los hermanos, pues se pueden defender mejor y pasan menos tiempo juntos.

- El temperamento impulsivo es mas frecuente en agresores y la falta de asertividad es mas frecuente en victimas. 
- Son más vulnerables para ser victimas los niños con problemas de aprendizaje, disfunciones orgánicas o algún problema físico o psicológico.

- Los hermanos que agreden a hermanos son menos empáticos hacia sus victimas potenciales, no tienen menos habilidades sociales sino que tienen valores y objetivos diferentes, además tienden a valorar las situaciones sociales como más hostiles atribuyendo hostilidad a otros.

En resumen, la violencia constituye en la actualidad un problema social de primer orden. Frente a las formas más graves y/o asentadas como fenómenos a combatir, están apareciendo "nuevas" manifestaciones; episodios de violencia graves a edades cada vez más tempranas, acoso escolar, violencia de hijos a padres, etc. Esta situación esta motivando planes y estrategias de sensibilización, prevención e intervención por parte de las administraciones públicas, organizaciones sociales y colectivos profesionales. Muchos de estos fenómenos se producen en el entorno familiar 0 es factible que su factor precipitador se encuentre en este ámbito. Frente a la dinámica de intervención y explicación victima - agresor, este artículo se suma a la corriente que aboga por la necesidad de un enfoque global sobre el origen y el mantenimiento de la violencia que se produce en el seno de las familias (Giddens, 2000, Trujano et al, 2006). Se trataría de fortalecer las capacidades, las relaciones afectivas y el equilibrio intrafamiliar, como vía para prevenir las conductas violentas en el futuro, en cualquiera de sus expresiones.

Esta pespectiva puede ser especialmente util a la hora de diseñar orienta- ciones preventivas generales (Moreno, 2005):

- La coherencia. Los padres deben tener y mantener el mismo criterio, que tiene que ser firme, tiene que tener continuidad y permanencia para no crear confusiones en el niño. Corregir desde el principio las conductas agresivas del hijo, no reírlas cómo si fueran una "gracia" del niño.

- La educación para la empatía y transmitir al hijo un afecto y unos valores basados en la comunicación y el respeto mutuos.

- La educación para la responsabilidad inculcando el binomio esfuerzo-responsabilidad hacia la colectividad. Los padres han de aprender a decir no al hijo, sin crispación, sin violencia, sin temor a que esta negativa provoque en el niño reacciones negativas en el presente 0 en el futuro. La permisividad no es educativa; inculcar pautas y pequeños hábitos de comportamiento hechos como rutina pone los fundamentos de una vida futura en que el niño sea capaz de asumir sus decisiones.

- Compartir tiempo de ocio y comunicación. No delegar la tarea educativa al mundo del ocio comercializado, sino convertir este ocio en un diálogo activo y creativo sobre los contenidos de los medios audiovisuales.

- La escuela ha de utilizar procedimientos inclusivos. La exclusión sistemática del niño que molesta puede ser un procedimiento generador de violencia: del aula al pasillo, del pasillo al patio y del patio a la calle. 
-La intervención en los jóvenes por un delito por violencia doméstica tiene que ser diferente a la que se hace por otras conductas delictivas, prioritaria- mente desde el ámbito de la salud mental familiar 0 individual, de la mediación comunitaria y del ámbito social (Romero y otros, 2005).

\section{BIBLIOGRAFÍA}

Alberdi, C. (2005) "Como reconocer y como erradicar la violencia contra las mujeres" en Violencia: Tolerancia cero. Obra Social "La Caixa" Barcelona.

Almeria (1995) Primera Conferencia Nacional de Consenso sobre el anciano maltratado,

Blumer, H. (1971), "Social problems as collective behaviour", Social problems, Volumen 18 , Numero 3, 1971, pp. 298-306.

Browne, K.; Herbert, M. (1997) Preventing family violence. Chichester: John Wiley \& Sons Ltd.

Consejo de Europa (1986) Violencia en la familia. Recomendación núm. R(85)4 adoptada por el Comité de Ministros el 26 de marzo de 1985 Estrasburgo

Chartier, J. P. [et alii] (2000) Los padres mártires. Madrid: Ed. Javier de Vergara.

Clemente, M. (1997) psicologia Social Aplicada. Ed Pirámide. Madrid.

Domenech, M./Ïñiguez, L. (2002) "La construcción social de la violencia” Atenea digital 2.

Egeland, B (1993) A history of abuse is a major risk factor for abusing the next generation. En R. Gelles y D. Loseke (Edts), Current controversies on family violence. Londres: Sage

Gelles, R. J. (1980) "Violence in the family: a review of research in the seventies. Journal of marriage and the family, 42, 873-885.

Gelles, R. J. (1993) "Family violence”, en Hampton, R. L; Gullota, T. P. (eds) Family violence. Pre vention and treatment. Londres: Sage Publications.

Gelles, R. J. (1997) Intimate Violence in Families. Thousand Oaks, CA: Sage Publications.

Giddes, A (2000) "La transformación de la intimidad. Sexualidad, amor y erotismo en las sociedades modernas". Madrid. Catedra.
Gómez, E./DE Paúl, J. (2002) "Transmisión intergeneracional del maltrato físico infantil: un estudio sobre el rol del apego adulto".En Bienestar y protección infantil. Volumen I, № 3, Paginas 97 118.

González, R. (2003) "Jóvenes y violencia. De lo complejo a lo operativo". Encuentros violencia social y juventud. Gobierno de Canarias. Mimeografiado.

González, M. P./ Muñoz, M.J. (2004) Violencia psicológica en las relaciones intimas de jóvenes y adolescentes www.aepc.es/resumenes.php $? q=$ ver\&id $=23$

González, R/Santana, J. (2001) "Violencia en parejas jóvenes". Psicothema Vol 13, nº 1. pags 127-131

Gracia, E./Musitu G. (1993) "El maltrato infantil. Un analisis ecologico de los factores de riesgo. Ed Ministerio de Asuntos Sociales. Madrid.

Horno, P. (2005) "Amor, poder y violencia" Save the Children España. Se puede descargar en www.savethechildren.es/interior.asp?IdItem $=1166$

IInstituto de la Mujer (2002). La violencia contra las mujeres. Madrid

López, F. (1994) "Abusos sexuales a menores. Lo que recuerdan de mayores". Madrid. Ministerio de Asuntos Sociales.

Martinez Roig, A./ PAUL, J. (1993): Maltrato y abandono en la infancia. Ed. Martinez Roca, Barcelona.

Milner, J. (1999) "Factores de riesgo". En Violencia contra niños. José Sanmartin (Editor) Ed Ariel. Barcelona pags 39 - 58

Montangu, A. (1978): La naturaleza de la agresividad humana. Alianza Universidad. Madrid

Moreno, F. X. (2005): Una violència emergent: 
Por un enfoque integral de la violencia familiar

els menors que agredeixen els seus pares. Full Informatiu Julio. COPC

Naouri, A. (2003) Padres permisivos, hijos tiranos. Barcelona: Ediciones B.

Oliva, A. (2002) Maltrato adolescente. Revista Bienestar y Protección Infantil. Vol 1. Número 1. Paginas 71-89.

Organización Mundial de la Salud (2002). Informe Mundial sobre Violencia y Salud, Ginebra OMS.

Pérez de Albéniz, A./de Paúl Ochotorena, J. (2002) "Empatia y maltrato físico infantil". En Intervención Psicosocial Vol 11, № 1 Pags 57-69

Rodríguez, N. (2004) ?Quién manda aquí!: Educar a los hijos con una disciplina coherente y efectiva. Barcelona: Ed. Juventud.

Ramos, M./Fuertes, A. (2005) Vulnerabilidad frente a la victimización sexual: factores psicosociales y contextuales asociados. Universidad de Salamanca, publicado en Revista de Sexologia Integral Vol. 2 N? Enero-marzo

Rojas Marcos, L. (2005) "Semillas y antídotos de la violencia en la intimidad". En Violencia: Tolerancia cero. Ed La Caixa.

Rodríguez, L./Rodríguez, F.J. (2004) Maltrato psicológico entre novios: epidemiologia y actitudes www.aepc.es/resumenes.php?q=ver\&id=16

Romero, F/Melero, A./Cánovas, C./Antolín, M. (2005) La violencia de los jóvenes en la familia: una aproximación a los menores denunciados por sus padres. CEJFE. Generalitat de Catalunya. www.gencat.net/dji/cejfe/cataleg_investigacions/S C.1.064.05\%20CAS.pdf

Sanmartín, J. (2000): La violencia y sus claves. Ed. Ariel. Barcelona. 4a edición. Pags. 13-21

Straus, M. A./Gelles, R. J./ Steinmetz (1988) Behind closed doors :violence in the American Family (editors). Newbury Park, CA: Sage Publications.

Trujano, P./Nava, C./Tejeda, E./Gutiérrez, S. (2006) Estudio confirmatorio acerca de la frecuencia y percepción de la violencia. Intervención Psicosocial Vol 15, Pags 95 - 110.

Yanes, J. M./González, R. (2000) Correlatos cognitivos asociados a la experiencia de violencia interparental. Psicothema Vol 12, nº 1. Pags 41- 48.

\section{WEBS RECOMENDADAS}

\section{Violencia en general}

Centro Reina Sofia para el Estudio de la Violencia: www.gua.es/violencia

Sociedad Española de Psicología de la Violencia: www.sepv.org

Instituto Español de Agresión y Familia: www.agresionyfamilia.com/ International Societyfor Research on Agression-ISRA. www.israsociety. com/ Minnesota Center Against Violence and Abuse. www.mincava.umn.edu

\section{Violencia contra la infancia y adolescencia}

Observatorio de la Infancia (Ministerio de Trabajo y Asuntos Sociales) : www.mtas.es/ inicioas/ observatoriodeinfancia/index.html

ISPCAN (International Society for Prevention of Child Abuse and Neglect) www.ispcan.org

FAPMI (Federación de Asociaciones para la Prevención del Maltrato Infantil) www.fapmi.es/

Save the Children: www.savethechildren.es

\section{Violencia en la pareja}

Organización Mundial De La Salud (OMS) Prevención Violencia contra la mujer www.who.int/ violence_injury_prevention/en/www.malostratos.co $m$ Womens against Violence Europe www.wavenetwork.org www.nodo50.org/mujeresred

Hombres por la igualdad www.hombresigualdad.com/ www.ahige.org/www. fundacionmujeres.es/mercurio/

\section{Violencia contra las personas mayores}

IMSERSO / PORTAL MAYORES www.imsersomayores.csic.es/salud/maltrato/

Acción Contra Los Malos Tratos A Las Personas Mayores www.elderabuse.org.uk

Red Internacional Para La Prevención Del Maltrato A Los Mayores (INPEA) www.inpea.net

National Center On Elder Abuse (NCEA) www.elderabusecenter.org

Organización Mundial De La Salud (OMS) www.who.int/hpr/ageing www.preventelderabuse.org 